\title{
Magnitude of thoracic spine deformity affecting morphologial characteristics of paraspinal muscles in patients with severe idiopathic scoliosis
}

\author{
E.N. Shchurova, G.N. Filimonova, S.O. Ryabykh
}

Ilizarov National Medical Research Centre for Traumatology and Orthopedics, Kurgan, Russian Federation

\begin{abstract}
Introduction Morphological, biochemical and histopathological characteristics of paraspinal muscles have been well described in patients with idiopathic scoliosis. However, there is a paucity of literature on morphological picture of paraspinal muscles in patients with severe idiopathic scoliosis. Objective To explore how the magnitude of thoracic spine deformity affects morphological characteristics of paraspinal muscles in patients with severe idiopathic scoliosis. Material and methods A total 21 patients with idiopathic scoliosis were reviewed. The patients were assigned to two groups depending on magnitude of preoperative thoracic spine deformity. A major group consisted of patients with scoliosis of $\geq 60^{\circ}(\mathrm{n}=11)$ and control group included patients with a curve $<60^{\circ}(\mathrm{n}=10)$. Biopsy samples were taken from muscle fragments (multifidus muscle) at the apex of the curve (major arc) at the Th6-Th10 level on the convex side while approaching to the posterior spinal structures during surgical correction of kyphoscoliosis using light microscope. The specimens were examined histologically with light microscope. Results Patients with severe idiopathic scoliosis $\left(\geq 60^{\circ}\right)$ showed evident muscle fiber atrophy and dystrophy of different extent. There were nucleus free areas and homogenized muscle fragments observed with connective tissue layers being swollen and frayed with multiple fibroblasts seen in nearly all the samples. Arterial walls were normally fibrotized. Structural changes ranged from minimal with a curve of $60^{\circ}$ to degrading muscles with the fibers replaced by fat and connective tissues with a curve angle of $145^{\circ}$. Conclusion Morphological characteristics of paraspinal muscles have been shown to be severely affected by the magnitude of thoracic spine deformity in patients with severe idiopathic scoliosis. The findings should be considered in surgical correction of kyphoscoliosis with special focus on postoperative vascular and neurotropic therapy to allow wound healing and lower complication rate.
\end{abstract}

Keywords: idiopathic scoliosis, paraspinal muscle, pathohistology, severe spine deformity

\section{INTRODUCTION}

Scoliosis of the spine is defined as a threedimensional deformity identified by curvature in the coronal plane and is often accompanied by vertebral rotation in the transverse plane and hypokyphosis in the sagittal plane. Scoliosis affects $0.2-0.6 \%$ of the population worldwide and accounts for approximately $70-90 \%$ of idiopathic cases without specific etiology [1-4]. The condition is multifactorial [1,5-11]. Among causative factors muscles of the human paraspinal region have been the focus of attention in patients with idiopathic scoliosis [8, 12-16]. Idiopathic scoliosis as a three-dimensional deformity is also characterized by impaired biomechanical parameters of other segments including shoulder, scapula, pelvis associated with the development of curvature with the paravertebral musculature exhibiting abnormalities as compensatory mechanisms in response to deformity or baseline structural changes $[10,17-$ 19]. Paraspinal muscle morphology and structure are generally explored in patients with idiopathic scoliosis measuring a mean of $48^{\circ}$ to $68^{\circ}$ (range, $28^{\circ}$ to $\left.115^{\circ}\right)[14,16,20-22]$. Surgical management of severe and rigid idiopathic scoliosis $\left(>60^{\circ}\right)[23,24]$ is a challenge [25]. Patients with idiopathic scoliosis present lower electromyographic activity in the paravertebral muscles of the thoracic spine after spine fusion, probably because of atrophy [26]. There is a limited number of papers reporting morphological evaluation of the paravertebral muscles in patients with severe and rigid idiopathic scoliosis [21,27].

Objective To explore how the magnitude of thoracic spine deformity affects morphological characteristics of paraspinal muscles in patients with severe idiopathic scoliosis.

Design Retrospective monocentric cohort casecontrol study. Level of evidence: 3b (UK Oxford, version 2009).

Patients were randomly recruited according to inclusion criteria:

- a single institution (clinic for spine pathology and rare diseases at the Kurgan Ilizarov Center) and period of recruitment 2015-2017;

- patients aged 12 to 30 years (inclusive) at the time of surgery;

- nosologic entity of thoracic idiopathic scoliosis (Lenke I-III).

Exclusion criteria were:

- patients with spinal curves of different etiology;

- patients with thoracolumbar (Lenke IV) and lumbar idiopathic scoliosis (Lenke V-VI);

- unavailability of the complete imaging archive for analysis.

Morphological evaluation of the paravertebral muscles was randomly performed for 21 patients with

[nd Shchurova E.N., Filimonova G.N., Ryabykh S.O. Magnitude of thoracic spine deformity affecting morphologial characteristics of paraspinal muscles in patients with severe idiopathic scoliosis. Genij Ortopedii, 2021, vol. 27, no 1, pp. 68-73. DOI 10.18019/10284427-2021-27-1-68-73 
the above criteria. Patients were assessed radiologically and morphologically. Outcomes measures included Cobb angle of the thoracic curve, histologic features of muscle fibers relative to the magnitude of the deformity. All patients underwent correction of the curve and spinal transpedicular fixation. Biopsy samples were taken from muscle fragments (multifidus muscle) at the apex of the curve (major arc) at the $\mathrm{Th}_{6}-\mathrm{Th}_{10}$ level on the convex side while approaching to the posterior spinal structures during surgical correction of kyphoscoliosis using light microscope. The samples were fixed in $10 \%$ neutral buffered formalin and then embedded in paraffin before sectioning. Representative sections were stained with hematoxylin and eosin (H\&E), Masson's trichrome stain according to Van Gieson staining protocols. The specimens were documented with AxioScope.A1 stereomicroscope and image acquisition performed with AxioCam digital camera (Carl Zeiss MicroImaging $\mathrm{GmbH}$, Germany). The study received a favourable opinion from the relevant research ethics committee of the Russian Ilizarov Scientific Center for Restorative Traumatology and Orthopaedics Ministry of Health of the Russian Federation. The study was performed in accordance with ethical principles for medical research involving human subjects stated in the Declaration of Helsinki developed by the World Medical Association. Written informed consent for the participation in the research project, diagnostic procedures and publication of the findings without identifying details was obtained from patients aged 18 years and older, the subject's parent/ legally acceptable representative. Microsoft Office Excell 2010 and AtteStat program were used to complete statistical data analysis reports. The data obtained were summarized as the arithmetic mean (M) and error of the arithmetic mean $( \pm \mathrm{m})$. We performed Student $\mathrm{t}$ tests for normally distributed variables and non-parametric tests for variables that were not normally distributed. We set the significance threshold at $\mathrm{p}=0.00066$.

\section{RESULTS}

Patients were assigned to two groups (main and control) according to the measurements of the curve (Table 1). Thoracic scoliosis measured $60^{\circ}$ to $145^{\circ}$ in the main group and $35^{\circ}$ to $55^{\circ}$ in controls. There were no statistically significant differences in age and gender between the groups.

Morphological evaluation of paraspinal muscles in patients with idiopathic scoliosis measuring $<60^{\circ}$ $\left(35-55^{\circ}\right)$ (control group) showed greater portion of FOV with mild fibrosis of endomysium and perimysium with muscle fibers maintaining polygonal profile and increased variability in the diameters in paraffin sections of intraoperative specimen (Fig. 1a). There were also muscle fibers with degenerative signs of different severity.

Arterial vessels had signs of mild fibrosis of the adventitious membrane, with no increase in volume, smooth myocytes of the tunica media were deprived of circular orientation with no fibrosis or obliteration (Fig. 1b). Intramuscular nerve guides had signs of normal histostructure with myelin nerve fibers maintained (Fig. 1c). Morphological evaluation of paraspinal muscles in patients with severe idiopathic scoliosis measuring $\geq 60^{\circ}$ showed evident atrophy of different severity and dystrophic muscle fibers. There were nuclei free and homogenized fragments of muscle fibers. Connective tissue layers appeared to be swollen and frayed with multiple fibroblasts in all the specimens. Arterial walls were mostly fibrous. The histostructure of the muscles had the smallest deviations from the norm with the thoracic curve measuring $60-65^{\circ}$ (Fig. 2). The diameters of the muscle fibers were relatively uniform in most fields of vision with the endomysium between the fibers being extrinsical. There were small diameter fibers observed along with giant hypertrophied fibers (Fig. 2a), degenerative and contractured fibers (Fig. 2b), endomysium fibrosis and hemorrhage (Fig. 2c) with perimyseum vessels being normally structured.

There were more visual fields with some interstitial fibrosis, several polygonal fiber profiles and few inactivated nuclei with the increased Cobb angle of $100-110^{\circ}$ (Fig. 3a). Histological patterns with small diameter fibers of rounded profiles were observed in a typical scenario of muscle structural adaptation. Muscle fibers with internal nuclei were identified indicating to a probable invasion of macrophages (Fig. 3b). The perimysium vessels had mostly normal histostructure. Arterial vessels with massive t. media and t. adventicia and almost complete obliteration of the lumen were noted (Fig. 3b). The vessels of the venous bed appeared to be thin, full of blood that could cause multiple hemorrhages.

Table 1

Major and compensatory curves measured in patients with idiopathic scoliosis, $M \pm m, n=21$

\begin{tabular}{|c|c|c|c|}
\hline \multirow{2}{*}{\multicolumn{2}{|c|}{ Description }} & \multicolumn{2}{|c|}{ Groups of patients } \\
\hline & & Main group $(n=11)$ & Control group $(\mathrm{n}=10)$ \\
\hline \multicolumn{2}{|c|}{ Age (years) } & $19.2 \pm 1.4$ (range, $14-27)$ & $16.5 \pm 0.9$ (range, $12-20)$ \\
\hline \multirow{2}{*}{ Gender } & male & 4 & 3 \\
\hline & female & 7 & 7 \\
\hline \multicolumn{2}{|c|}{ Major curve at $\mathrm{Th}_{6}-\mathrm{Th}_{10}$ level, ${ }^{0}$} & $97.3 \pm 7.9 *$ (range, $60-145)$ & $47.4 \pm 3.6$ (range, $35-55)$ \\
\hline \multicolumn{2}{|c|}{ Compensatory curve at $\mathrm{L}_{1}-\mathrm{L}_{3}$ level, ${ }^{0}$} & $47.3 \pm 9.7$ (range, $15-135)$ & $27.1 \pm 5.1$ (range, $15-43$ ) \\
\hline
\end{tabular}

Note: ${ }^{*}$, significant differences in parameters of the main and control groups at $p=0.00066$. 

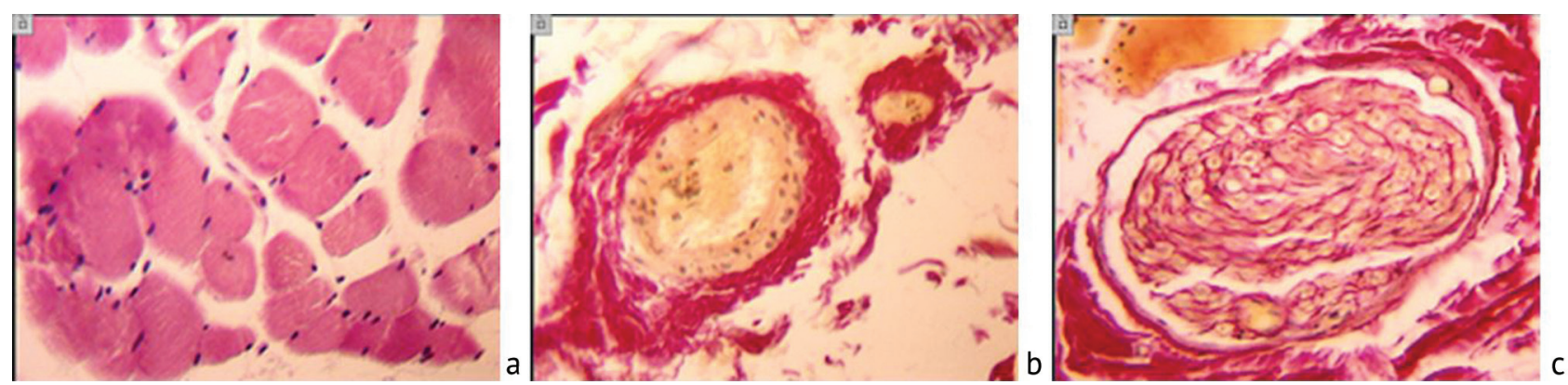

Fig. 1 Fragments of paraffin sections of paravertebral muscle specimen at the apex of the curve in patients with idiopathic scoliosis measuring $40^{\circ}$ at the thorax showing $(\boldsymbol{a})$ mild fibrosis of the endomysium; $(\boldsymbol{b})$ vessels of the arterial bed with signs of mild fibrosis of the adventitious membrane, the tunica media with no increase in volume, smooth myocytes deprived of circular orientation; (c) normal histostructure of the nerve guides maintained. Stained with H\&E (a), Masson's trichrome (b, $)$; magnification 200×
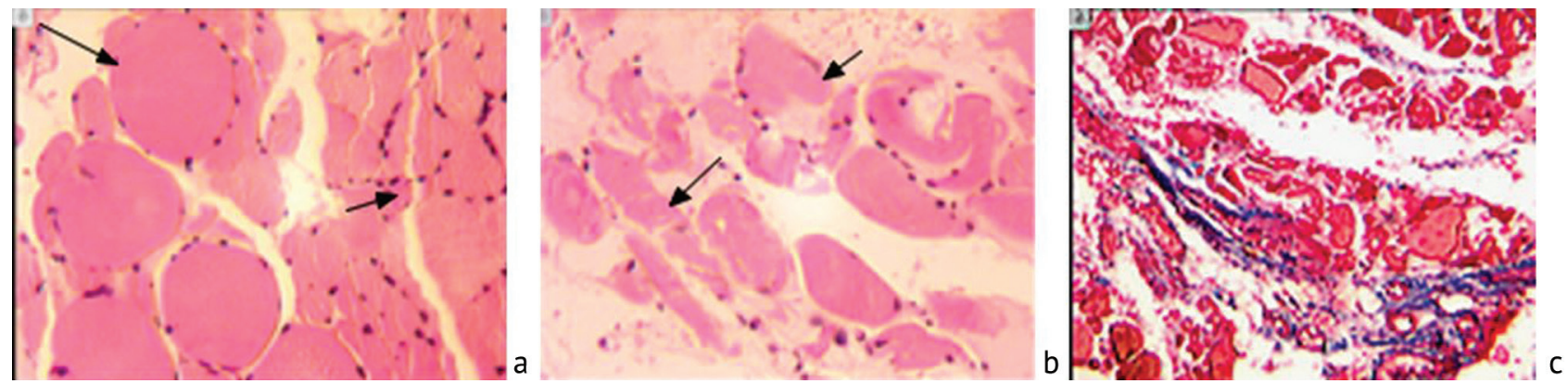

Fig. 2 Fragments of paraffin sections of paravertebral muscle biopsies at the apex of deformity in patients with idiopathic scoliosis with an a Cobb angle of $60^{\circ}$ showing $(a)$ variations in the diameters of muscle fibers featuring hypertrophied (arrow) and small atrophic fibers (short arrow); (b) contractured fiber (arrow) at the initial stage of degeneration (short arrow); (c) a site of interstitial fibrosis, hemorrhage. Stained with H\&E $(\boldsymbol{a}, \boldsymbol{b})$; Masson's trichrome $(\boldsymbol{c})$; magnification 200×
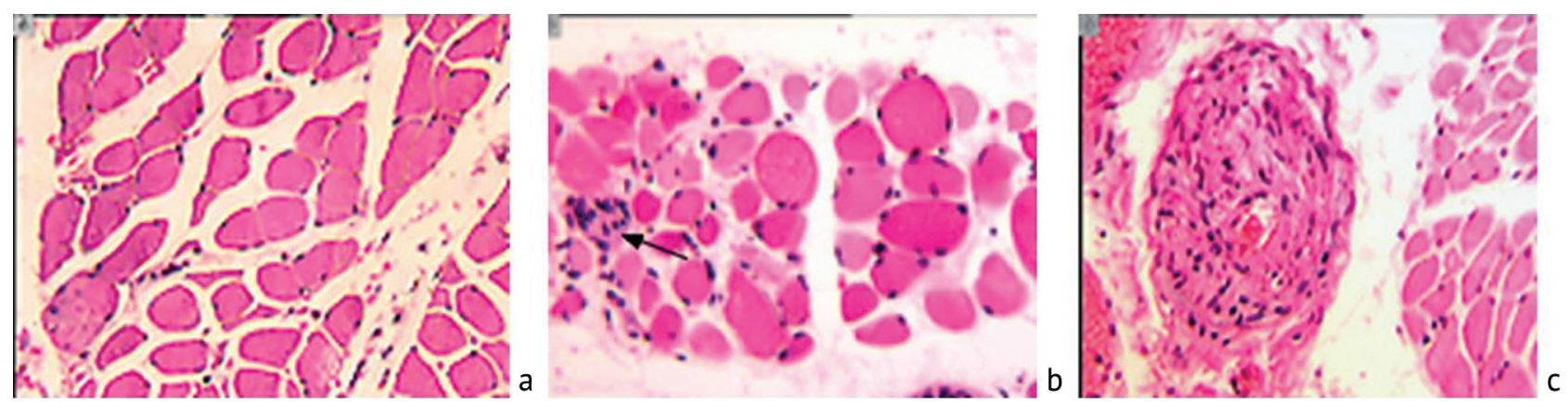

Fig. 3 Fragments of paraffin sections of biopsies of paraspinal muscles at the top of deformity in patients with idiopathic scoliosis with a Cobb angle of $110^{\circ}$ showing $(\boldsymbol{a})$ profiles of many fibers retaining polygonality, interstitial space fibrosis; (b) rounded fibers of small diameters, fibers with multiple internal nuclei (arrow); (c) an artery with severe fibrosis and complete obliteration of the lumen. Stained with H\&E; magnification 200×

The paraspinal muscles had greater signs of adipocytes and fibrosis (Fig. 4a). The perimysium vessels degeneration with the maximum thoracic curve of had significantly thickened membranes (Fig. 4b). Signs $145^{\circ}$ in the study specimen. Normal muscle tissue was nearly absent with the muscle fibers being replaced by of axonopathy and lipomatosis, proliferated fibrous tissue were identofied in the nerve conductors (Fig. 4c).
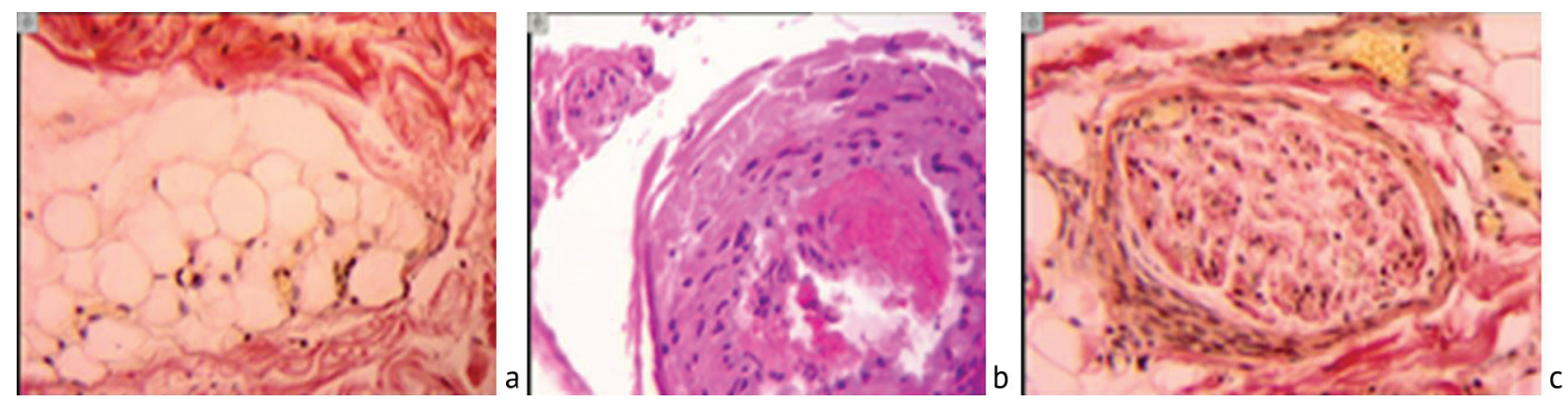

Fig. 4 Fragments of paraffin sections of paravertebral muscle biopsies at the top of the deformity in patients with idiopathic scoliosis of $145^{\circ}$ showing $(\boldsymbol{a})$ fatty degeneration of muscle fibers, interstitial space fibrosis; $(\boldsymbol{b})$ severe fibrosis of the arterial membranes, disorientation of smooth muscle fibers; $(\boldsymbol{c})$ proliferation of fibrous tissue, signs of axonopathy in the nerve conductor. Paraffin sections stained with Van Gieson method $(\boldsymbol{a}, \boldsymbol{c}), \mathrm{H} \& \mathrm{E}(\boldsymbol{b})$; magnification 200× 


\section{DISCUSSION}

Torso muscle imbalance is an important factor for the onset and progression of idiopathic scoliosis [28]. C. Wong et al. suggested a theory of muscle balancing/realigning to describe the mechanism of muscle imbalance causing the curve progression [29]. The findings of genetic studies have shown that some risk loci for idiopathic scoliosis are likely to develop in areas located near or inside genes linked with muscle biogenesis [30, 31]. MRI and ultrasonographic findings of paravertebral muscles in patients with idiopathic scoliosis demonstrated different changes in electromyographic activity [19, 22, 32-35], histological characteristics [14, 21, 27, $36]$ and structures $[16,37,38]$. M. Wajchenberg et al. reported biopsy performed during surgery as the best way to assess pathological changes in muscles. Previous studies conducted with percutaneous biopsies or through electromyography could not adequately isolate the proper muscle fibers [21].

Since the beginning of the 70 s of the last century, studies have been conducted to characterize the morphological, morphometric and ultrastructural features of the paraspinal muscles in idiopathic scoliosis. A wide range of pathological changes in the normal distribution of the majority of muscle fiber types was seen with light and electron microscopy. The alterations appeared to be mostly non-specific [36]. Hypertrophy, atrophy, centralization of nuclei, sarcotubular myopathy [39, 40], disruption of myofilaments, subsarcolemmal accumulation of glycogen, lipids and mitochondria with atypical ultrastructure were noted in some myocytes [41]. Signs of myopathy, necrosis, fibrosis and fat involution, and hyaline fibers were identified in the fibers [21]. The few pathologic changes were predominately seen in the gravest cases of scoliosis [27].

Moderate morphological changes were detected in $50 \%$ of histological studies and were deemed as variations of the norm. Necrosis, phagocytosis, hypertrophy and fiber regeneration were observed in a few specimens with a greater percentage of the manifestations being characteristic for the muscles on the concave side of the curve [14]. The role of localization of most pathohistological changes to be identified in the paraspinal muscles either on the concave or convex side of the curve has not been fully understood in patients with idiopathic scoliosis. M. Wajchenberg et al. reported significantly more fibrosis and fatty involution in the paraspinal muscles on the concave side of the scoliosis apex than on the convex side. However, both sides showed signs of myopathy, muscular atrophy due to necrosis, presence of hyaline fibers [21]. Yarom R. and Khosla S. suggested that the maximum morphological changes in the paravertebral muscles were also identified on the concave side of the deformity in this cohort of patients $[39,40]$. Paz A.C.D. reported greater morphological changes on the convex side [14]. Slager U. T. reported no preferences for either side of the curve [40].

There is also no consensus about muscle volume (according to MRI data) regarding the side of the curve. A larger back muscle volume in idiopathic scoliosis patients can be more frequent on the concave than on the convex side [37]. Jiang J. et al. [16] reported a larger muscle volume observed, on the contrary, on the convex side of the scoliotic curve.

Publications reporting structural and morphological changes in the paraspinal muscles in idiopathic scoliosis normally review the specimens taken from patients with an average curve angle of $48^{\circ}$ to $68^{\circ}$ (range, $28^{\circ}$ to $115^{\circ}$ ) $[14,15,16,20,22]$. Treatment of severe spinal deformities $\left(>60^{\circ}\right.$ degrees) $[23,24]$ remains a serious surgical problem [25]. The paraspinal muscles of the thoracic spine have shown lower activity after spinal fusion due to atrophy [26]. However, little attention has been paid to the study of the morphology of paravertebral muscles in patients with severe idiopathic scoliosis. In this study, we analyzed the effect of the angle of spinal deformity in the thoracic region on the morphological features of the paravertebral muscles on the convex side of the deformity in idiopathic scoliosis, depending on the severity of the curvature.

The greater angle of deformation is known to be associated with greater changes in electromyographic activity with a curve of $10^{\circ}$ to $40^{\circ}$ [33]. A. C. D. Paz et al. reported fiber diameter data being significantly correlated with the Cobb angle values mesuring $45^{\circ}$ to $90^{\circ}$ with the mean of $64^{\circ}$. Statistical analysis showed an inverse relationship: the diameter of both type I and type II fibers of the paraspinal muscle on the concave side decreased with increasing Cobb angle [14]. The greater the Cobb angle measuring $32^{\circ}$ to $73^{\circ}$ with the mean of $51^{\circ}$, the greater the difference in the number of muscle fibers on the convex and concave sides observed [22].

Our findings showed different severity of atrophy and dystrophy of muscle fibers in patients with severe idiopathic scoliosis of $\geq 60^{\circ}$. The histostructure of the muscles appeared to have minimal deviations 
from the norm in the thoracic curve measuring 60 $65^{\circ}$. In addition to muscle atrophy, hypertrophy was reported in the curve measuring $28^{\circ}-45^{\circ}$ to $90^{\circ}$ with the mean of $56^{\circ}[14,16,39,40]$. The curve angle increased to $100-110^{\circ}$ degrees was associated with greater visual fields showing polygonal fiber profiles and moderately pronounced interstitial tissue. Muscle fibers of a very small diameter were also observed in the specimens indicating to the muscle structural adaptation. The accumulation of internal nuclei in fibers could be ascribed either to myophagy (invasion of macrophages) or to pycnotic nuclear clusters in myodystrophy [42]. Fibrosis of the endomysium and perimysium, areas of adipocytes and multiple hemorrhages were consistent with the literature data. Histological examination of the paravertebral muscles of patients with thoracic curves of $46^{\circ}$ to $115^{\circ}$ with the mean of $68^{\circ}$ showed interstitial fibrosis, signs of myopathy, necrosis and fatty involution [15].
These changes were reported to be more common on the convex side [14].

Different authors have emphasized that patients with idiopathic scoliosis who require surgical treatment may have a more severe deformity, that can lead to significant pathohistological changes in the paraspinal muscles $[15,21]$. However, no description of the morphological manifestations of the back muscles in patients with thoracic curve of $>120^{\circ}$ could be found in the available literature. Our findings showed greater signs of degeneration seen in the paraspinal muscles with the maximal angle of the thoracic curve measuring $145^{\circ}$. The muscle tissue appeared to degrade as the structure with muscle fibers being replaced with adipose and connective tissue. Muscle fibers were shown to be fragmented with perimysium vessels featuring thickened membranes. Signs of axonopathy and lipomatosis were observed in nerve conductors with nerve fibers being replaced with fibrous tissue.

\section{CONCLUSION}

Morphological characteristics of paraspinal muscles were shown to be severely affected by the magnitude of thoracic spine deformity in patients with idiopathic scoliosis. The structural muscle changes ranged from minimal alterations with a curve measuring up to $60^{\circ}$ to the muscle tissue degrading as the structure with the fibers being replaced with adipose and connective tissue with the curve of $145^{\circ}$. Patients with severe idiopathic scoliosis $\left(\geq 60^{\circ}\right)$ showed evident muscle fiber atrophy and dystrophy of different extent, an expansion of fibroblastic connective tissue and arterial walls. The findings should be considered in surgical correction of kyphoscoliosis with special focus on postoperative vascular and neurotropic therapy to allow wound healing and lower complication rate.

\section{REFERENCES}

1. Trobisch P., Suess O., Schwab F. Idiopathic scoliosis. Dtsch. Arztebl. Int., 2010, vol. 107, no. 49, pp. 875-884. DOI: 10.3238/arztebl.2010.0875.

2. Negrini S., Aulisa A.G., Aulisa L., Circo A.B., De Mauroy J.C., Durmala J., Grivas T.B., Knott P., Kotwicki T., Maruyama T., Minozzi S., O'Brien J.P., Papadopoulos D., Rigo M., Rivard C.H., Romano M., Wynne J.H., Villagrasa M., Weiss H.R., Zaina F. SOSORT guidelines: Orthopaedic and Rehabilitation treatment of idiopathic scoliosis during growth. Scoliosis, 2012, vol. 7, no. 1, pp. 3. DOI: 10.1186/1748-7161-7-3.

3. Stylianides G.A., Beaulieu M., Dalleau G., Rivard C.H., Allard P. Iliac crest orientation and geometry in able-bodied and non-treated adolescent idiopathic scoliosis girls with moderate and severe spinal deformity. Eur. Spine J., 2012, vol. 21, no. 4, pp. 725-732. DOI: 10.1007/s00586-011-2070-5.

4. Ovadia D. Classification of adolescent idiopathic scoliosis (AIS). J. Child. Orthop., 2013, vol. 7, no. 1, pp. 25-28. DOI: 10.1007/s11832-012-0459-2.

5. Cheung K.M., Wang T., Qiu G.X., Luk K.D. Recent advances in the aetiology of adolescent idiopathic scoliosis. Int. Orthop., 2008, vol. 32, no. 6, pp. 729-734. DOI: 10.1007/s00264-007-0393-y.

6. Dudin M.G., Pinchuk D.Iu. Idiopaticheskii Skolioz: neirofiziologiia, neirokhimiia [Idiopathic Scoliosis: neurophysiology, neurochemistry]. SPb., Chelovek, 2013, 304 p. (in Russian)

7. Burwell R.G., Dangerfield P.H., Moulton A., Grivas T.B., Cheng J.C. Whither the etiopathogenesis (and scoliogeny) of adolescent idiopathic scoliosis? Incorporating presentations on scoliogeny at the 2012 IRSSD and SRS meetings. Scoliosis, 2013, vol. 8, no. 1, pp. 4. DOI: 10.1186/1748-7161-8-4.

8. Diab A.A. The role of forward head correction in management of adolescent idiopathic scoliotic patients: a randomized controlled trial. Clin. Rehabil., 2012, vol. 26, no. 12, pp. 1123-1132. DOI: 10.1177/0269215512447085.

9. Latalski M., Danielewicz Bromberek A., Fatyga M., Latalska M., Kröber M., Zwolak P. Current insights into the aetiology of adolescent idiopathic scoliosis. Arch. Orthop. Trauma Surg., 2017, vol. 137, no. 10, pp. 1327-1333. DOI: 10.1007/s00402-017-2756-1.

10. De Sèze M., Cugy E. Pathogenesis of idiopathic scoliosis: a review. Ann. Phys. Rehabil. Med., 2012, vol. 55, no. 2, pp. 128-138. DOI: 10.1016/j. rehab.2012.01.003.

11. Yaman O., Dalbayrak S. Idiopathic scoliosis. Turk. Neurosurg., 2014, vol. 24, no. 5, pp. 646-657. DOI: 10.5137/1019-5149.JTN.8838-13.0.

12. Veldhuizen A.G., Wever D.J., Webb P.J. The aetiology of idiopathic scoliosis: biomechanical and neuromuscular factors. Eur. Spine J., 2000, vol. 9, no. 3, pp. 178-184. DOI: $10.1007 / \mathrm{s} 005860000142$.

13. Weiss H.R., Goodall D. The treatment of adolescent idiopathic scoliosis (AIS) according to present evidence. A systematic review. Eur. J. Phys. Rehabil. Med., 2008, vol. 44, no. 2, pp. 177-193.

14. Paz A.C., Brandao I., Silveira E.B., Gomes C.R. Morphological and Morphometric Analysis of Paraspinal and Intercostal Musculature on Adolescent Idiopathic Scoliosis. J. Spine, 2015, vol. 4, no. 1, pp. 1000206. DOI:10.4172/2165-7939.1000206.

15. Wajchenberg M., Astur N., Kanas M., Martins D.E. Adolescent idiopathic sco $\neg$ liosis: current concepts on neurological and muscular etiologies. Scoliosis Spinal Disord., 2016, vol. 11, pp. 4. DOI 10.1186/s13013-016-0066-y.

16. Jiang J., Meng Y., Jin X., Zhang C., Zhao J., Wang C., Gao R., Zhou X. Volumetric and Fatty Infiltration Imbalance of Deep Paravertebral Muscles in Adolescent Idiopathic Scoliosis. Med. Sci. Monit., 2017, vol. 23, pp. 2089-2095. DOI: 10.12659/MSM.902455.

17. Zabjek K.F., Leroux M.A., Coillard C., Prince F., Rivard C.H. Postural characteristics of adolescents with idiopathic scoliosis. J. Pediatr. Orthop., 2008, vol. 28, no. 2, pp. 218-224. DOI: 10.1097/BPO.0b013e3181651bdc. 
18. Fabry G. Clinical practice: the spine from birth to adolescence. Eur. J. Pediatr., 2009, vol. 168, no. 12, pp. 1415-1420. DOI: 10.1007/s00431-009-0998-9. 19. Chwała W., Koziana A., Kasperczyk T., Walaszek R., Płaszewski M. Electromyographic assessment of functional symmetry of paraspinal muscles during static exercises in adolescents with idiopathic scoliosis. Biomed. Res. Int., 2014, vol. 2014, pp. 573276. DOI: 10.1155/2014/573276.

20. Mannion A.F., Meier M., Grob D., Müntener M. Paraspinal muscle fibre type alterations associated with scoliosis: an old problem revisited with new evidence. Eur. Spine J., 1998, vol. 7, no. 4, pp. 289-293. DOI: 10.1007/s005860050077.

21. Wajchenberg M., Martins D.E., De Paiva Luciano R., Puertas E.B., Del Curto D., Schmidt B., Oliveira A.B., Faloppa F. Histochemical analysis of paraspinal rotator muscles from patients with adolescent idiopathic scoliosis: a cross-sectional study. Medicine (Baltimore), 2015, vol. 94, no. 8, pp. e598. DOI: 10.1097/MD.0000000000000598.

22. Stetkarova I., Zamecnik J., Bocek V., Vasko P., Brabec K., Krbec M. Electrophysiological and histological changes of paraspinal muscles in adolescent idiopathic scoliosis. Eur. Spine J., 2016, vol. 25, no. 10, pp. 3146-3153. DOI:10.1007/s00586-016-4628-8.

23. Greiner K.A. Adolescent idiopathic scoliosis: radiologic decision-making. Am. Fam. Physician, 2002, vol. 65, no. 9, pp. 1817-1822.

24. Koptan W., ElMiligui Y. Three-staged correction of severe rigid idiopathic scoliosis using limited halo-gravity traction. Eur. Spine J., 2012, vol. 21, no. 6, pp. 1091-1098. DOI: 10.1007/s00586-011-2111-0.

25. Teixeira da Silva L.E., de Barros A.G., de Azevedo G.B. Management of severe and rigid idiopathic scoliosis. Eur. J. Orthop. Surg. Traumatol., 2015, vol. 25, no. Suppl. 1, pp. S7-12. DOI: 10.1007/s00590-015-1650-1.

26. Lu W.W., Hu Y., Luk K.D., Cheung K.M., Leong J.C. Paraspinal muscle activities of patients with scoliosis after spine fusion: an electromyographic study. Spine, 2002, vol. 27, no. 11, pp. 1180-1185. DOI: 10.1097/00007632-200206010-00009.

27. Zetterberg C., Aniansson A., Grimby G. Morphology of the paravertebral muscles in adolescent idiopathic scoliosis. Spine, 1983, vol. 8, no. 5, pp. 457-462. DOI: 10.1097/00007632-198307000-00003.

28. Modi H.N., Suh S.W., Yang J.H., Hong J.Y., Venkatesh K., Muzaffar N. Spontaneous regression of curve in im $\neg$ mature idiopathic scoliosis - does spinal column play a role to balance? An observation with literature review. J. Orthop. Surg. Res., 2010, vol. 5, pp. 80. DOI: 10.1186/1749-799X-5-80.

29. Wong C. Mechanism of right thoracic adolescent idiopathic scoliosis at risk for progression; a unifying pathway of development by normal growth and imbalance. Scoliosis, 2015, vol. 10, pp. 2. DOI: 10.1186/s13013-015-0030-2.

30. Sharma S., Londono D., Eckalbar W.L., Gao X., Zhang D., Mauldin K., Kou I., Takahashi A., Matsumoto M., Kamiya N., Murphy K.K., Cornelia R.; TSRHC Scoliosis Clinical Group; Japan Scoliosis Clinical Research Group, Herring J.A., Burns D., Ahituv N., Ikegawa S., Gordon D., Wise C.A. A PAX1 enhancer locus is asso-ciated with susceptibility to idiopathic scoliosis in females. Nat. Commun., 2015, vol. 6, pp. 6452. DOI: 10.1038/ncomms7452.

31. Zhu Z., Tang N.L., Xu L., Qin X., Mao S., Song Y., Liu L., Li F., Liu P., Yi L., Chang J., Jiang L., Ng B.K., Shi B., Zhang W., Qiao J., Sun X., Qiu X., Wang Z., Wang F., Xie D., Chen L., Chen Z., Jin M., Han X., Hu Z., Zhang Z., Liu Z., Zhu F., Qian B.P., Yu Y., Wang B., Lee K.M., Lee W.Y.W., Lam T.P., Qiu Y., Cheng J.C. Genome-wide association study identifies new susceptibility loci for adolescent idiopathic scoliosis in Chinese girls. Nat. Commun., 2015, vol. 6, pp. 8355. DOI: $10.1038 /$ ncomms9355.

32. Vitenzon A.S., Skoblin A.A., Alekseenko I.G. Izmenenie funktsii myshts tulovishcha i nizhnikh konechnostei pri idiopaticheskom skolioze II-III stepeni [Changes in the function of the body and lower limb muscles in II-III Degree idiopathic scoliosis]. Khirurgiia Pozvonochnika, 2007, no. 3, pp. 31-35. (in Russian)

33. Tsai Y.T., Leong C.P., Huang Y.C., Kuo S.H., Wang H.C., Yeh H.C., Lau Y.C. The electromyographic responses of paraspinal muscles during isokinetic exercise in adolescents with idiopathic scoliosis with a Cobb's angle less than fifty degrees. Chang Gung Med. J., 2010, vol. 33, no. 5, pp. 540-550.

34. Farahpour N., Ghasemi S., Allard P., Saba M.S. Electromyographic responses of erector spinae and lower limb's muscles to dynamic postural per-turbations in patients with adolescent idiopathic scoliosis. J. Electromyogr. Kinesiol., 2014, vol. 24, no. 5, pp. 645-651. DOI: 10.1016/j. jelekin.2014.05.014.

35. Lédio Alves D.P., De Araújo B. Muscle disorders in adolescent idiopathic scoliosis: Literature review. Coluna/Columna, 2016, vol. 15, no. 1, pp. 7377. DOI: $10.1590 / \mathrm{S} 1808-185120161501151839$.

36. Yarom R., Robin G.C. Muscle pathology in idiopathic scoliosis. Isr. J. Med. Sci., 1979, vol. 15, no. 11, pp. 917-924.

37. Zoabli G., Mathieu P.A., Aubin C.E. Back muscles biometry in adolescent idiopathic scoliosis. Spine J., 2007, vol. 7, no. 3, pp. 338-344. DOI: 10.1016/j.spinee.2006.04.001.

38. Zapata K.A., Wang-Price S.S., Sucato D.J., Dempsey-Robertson M. Ultrasonographic measurements of paraspinal muscle thickness in adolescent idiopathic scoliosis: a comparison and reliability study. Pediatr. Phys. Ther., 2015, vol. 27, no. 2, pp. 119-125. DOI: 10.1097/PEP.0000000000000131.

39. Khosla S., Tredwell S.J., Day B., Shinn S.L., Ovalle W.K. Jr. An ultrastructural study of multifidus muscle in progressive idiopathic scoliosis Changes resulting from a sarcolemmal defect at the myotendinous junction. J. Neurol. Sci., 1980, vol. 46, no. 1, pp. 13-31. DOI: 10.1016/0022$510 x(80) 90040-4$

40. Slager U.T., Hsu J.D. Morphometry and pathology of the paraspinous muscles in idiopathic scoliosis. Dev. Med. Child. Neurol., 1986, vol. 28, no. 6, pp. 749-756. DOI: $10.1111 /$ j.1469-8749.1986.tb03928.x.

41. Sahgal V., Shah A., Flanagan N., Schaffer M., Kane W., Subramani V., Singh H. Morphologic and morphometric studies of muscle in idiopathic scoliosis. Acta Orthop. Scand., 1983, vol. 54, no. 2, pp. 242-251. DOI: 10.3109/17453678308996564.

42. Neuromuscular Disease Center. Washington University, St. Louis, MO USA. September 2018. Available at: http://neuromuscular.wustl.edu/index. $\mathrm{html}$ (accessed 15.03.2019).

Received: 22.04 .2019

\section{Information about the authors:}

1. Elena N. Shchurova, Ph.D. of Biological Sci.,

Ilizarov National Medical Research Centre for Traumatology and Orthopedics, Kurgan, Russian Federation, Email: elena.shurova@mail.ru

2. Galina N. Filimonova, Ph.D. of Biological Sci.,

Ilizarov National Medical Research Centre for Traumatology and Orthopedics, Kurgan, Russian Federation,

3. Sergey O. Ryabykh, M.D., Ph.D.,

Ilizarov National Medical Research Centre for Traumatology and Orthopedics, Kurgan, Russian Federation,

Email: rso_@mail.ru 